\title{
Study of Transport Properties of Tris (hydroxymethyl)aminomethane Hydrochloride in 20\% (v/v) Acetone-Water System at $303.15^{\circ} \mathrm{K}$
}

\author{
Ajita Dixit \\ Rungta College of Engineering and Technology, Near Nandanvan, Veer Savarkar, Nagar, Raipur (CG) 492010, India \\ Correspondence should be addressed to Ajita Dixit; ajita.dixit@gmail.com
}

Received 23 April 2013; Accepted 18 July 2013

Academic Editor: Stoyan Karakashev

Copyright (C) 2013 Ajita Dixit. This is an open access article distributed under the Creative Commons Attribution License, which permits unrestricted use, distribution, and reproduction in any medium, provided the original work is properly cited.

\begin{abstract}
Viscometric properties of Tris-(hydroxymethyl)amino methane hydrochloride are measured in 20\% (v/v) acetone-water system $303.15^{\circ} \mathrm{K}$. The related parameters are the experimental values of viscosity $(\eta)$ allow to determine relative viscosity $\left(\eta_{r}\right)$, viscosity $B$-coefficient of the Jones-Dole equation, free energies of activation of viscous flow $\Delta \mu_{1}^{0 \neq}$ and $\Delta \mu_{2}^{0 \neq}$ per mole solvent, and solute, respectively. The excess molar volume, excess viscosity, excess Gibb's free energy, and interaction parameter of Grunberg and Nissan have also been calculated. These studies are of great help in characterizing the structure and properties of solutions. The addition of an organic solvent to water brings about a sharp change in the solvation of ions.
\end{abstract}

\section{Introduction}

The density is one of the key thermodynamic properties of electrolyte solutions and belongs with an equilibrium property, while the viscosity is one of the key transport properties of electrolyte solutions and belongs with a dynamic state property. Both of them rein dispensable basic data to engineering design and process optimization. Knowledge of viscometric properties studied in binary solvent system is useful for engineering design of new applications. Viscosities are important physico-chemical parameters widely studied in aqueous, aqueous-organic, and others [1]. The density and viscosity are important basic data used in chemical engineering designs, solution theory, and molecular thermodynamics [2]. Physicochemical processes of electrolyte solutions are of considerable interest due to their importance in numerous industrial processes. Extensive experimental viscosity data are available for mixed-solvent system. In mixed-solvent electrolyte solutions, viscosity is affected by the concentration of electrolytes but also by the composition of the solvent. Even the viscosity of solvent mixtures may show a complex behavior and change significantly with composition. The knowledge of physico-chemical properties of liquid mixtures of two or more components are of theoretical and industrial importance due to their wide range of applicability as solvent media in various physico-chemical processes. In the present investigation following parameters are measured by Viscosity data of tris (hydroxymethyl)aminomethane hydrochloride is measured in $20 \%(\mathrm{v} / \mathrm{v})$ acetone-water system $303.15^{\circ} \mathrm{K}$ is used to determine $B$-coefficient $(B)$ and constant characteristic of ion-ion interactions $(A)$ excess viscosity $\left(V^{E}\right)$, and excess molar free energy of activation of flow $\left(G^{E}\right)$. The interaction parameters Gruenberg and Nissan $(d)$ were also calculated and reported. The parameters are analyzed to be evaluated to understand solute-solvent interaction.

\section{Experiment}

A stock solution of $0.100 \mathrm{M}$ tris (hydroxymethyl)aminomethane hydrochloride is prepared in $20 \%(\mathrm{v} / \mathrm{v})$ acetonewater solvent by direct weighing. Mass dilution technique used for preparation of other concentrations. The concentration of the solutions involved in the experiment was taken in range from $0.010 \mathrm{M}$ to $0.100 \mathrm{M}$. Mass dilution technique was applied to prepare the solution of different concentration. Viscosities were measured by capillary viscometer of ostwaldSprengel type (MaHaRaNa, Instruments MFG-Company 
TABLE 1: Viscosities and densities of tris (hydroxymethyl)aminomethane hydrochloride in $20 \%(\mathrm{v} / \mathrm{v})$ acetone-water system at $303.15^{\circ} \mathrm{K}$.

\begin{tabular}{lcc}
\hline $\begin{array}{l}\text { Concentration } \\
\left(\mathrm{mol} \mathrm{dm}^{-3}\right)\end{array}$ & $\begin{array}{c}\text { Density }(\rho) \\
\mathrm{gm} \mathrm{cm}^{-3}\end{array}$ & $\begin{array}{c}\text { Viscosity }(\eta) \\
\mathrm{mPa} \mathrm{s}\end{array}$ \\
\hline 0.0100 & 0.9436 & 0.9307 \\
0.0200 & 0.9446 & 0.9678 \\
0.0300 & 0.9458 & 1.0142 \\
0.0400 & 0.9465 & 1.0344 \\
0.0500 & 0.9475 & 1.1196 \\
0.0600 & 0.9493 & 1.1671 \\
0.0700 & 0.9506 & 1.2337 \\
0.0800 & 0.9528 & 1.3015 \\
0.0900 & 0.9541 & 1.3686 \\
0.1000 & 0.9551 & 1.5004 \\
\hline
\end{tabular}

TABLE 2: Excess molar volume and excess viscosity of tris (hydroxymethyl)aminomethane hydrochloride in $20 \%(\mathrm{v} / \mathrm{v})$ acetone-water system at $303.15^{\circ} \mathrm{K}$.

\begin{tabular}{lcc}
\hline $\begin{array}{l}\text { Concentration } \\
\left(\mathrm{mol} \mathrm{dm}^{-3}\right)\end{array}$ & $\begin{array}{c}\text { Excess molar volume } \\
\left(V^{E}\right)\end{array}$ & $\begin{array}{c}\text { Excess viscosity } \\
\left(\eta^{E}\right)\end{array}$ \\
\hline 0.0100 & 1.2691 & -0.0257 \\
0.0200 & 0.2639 & 0.0113 \\
0.0300 & 0.2360 & 0.0577 \\
0.0400 & 0.2169 & 0.0780 \\
0.0500 & 0.1935 & 0.1632 \\
0.0600 & 0.1526 & 0.2107 \\
0.0700 & 0.1206 & 0.2773 \\
0.0800 & 0.0713 & 0.3452 \\
0.0900 & 0.0396 & 0.4122 \\
0.1000 & 0.0165 & 0.5441 \\
\hline
\end{tabular}

(I am not related to MFG company commercially.), Ajmer India) with accuracy of $0.1 \mathrm{~K}$. The Viscometer was calibrated with triple distilled water. Viscosity values were determined using the relation,

$$
\eta=\rho\left(K t-\frac{L}{t}\right)
$$

where $\eta$ is a viscosity, $\rho$ is the density of the liquid, $t$ is the flow time, and $K$ and $L$ are constants for given viscometer. The flow time was measured with digital stop watch with accuracy of $\pm 0.01 \mathrm{sec}$. The $K$ and $L$ were obtained by measuring the flow time of triple distilled water at temperature $303.15^{\circ} \mathrm{K}$. All measurements were carried out in triplicate.

\section{Result and Discussion}

3.1. Viscosities and Densities. The values of viscosities and densities are reported in Table 1 . Viscosities of the solution are increasing with the increase in concentration.

\subsection{Excess Molar Volume and Excess Viscosity}

3.2.1. Excess Molar Volume. It is calculated from following expression:

$$
V^{E}=V-\left(X_{1} V_{1}+X_{2} V_{2}\right),
$$

where $V=$ Molar volume of Tris-(hydroxymethyl)amino methane hydrochloride solution, $V_{1}=$ Molar volume of mixed solvent, $V_{2}=$ Molar volume of solute, $X_{1}=$ Mole fraction of solvent, and $X_{2}=$ Mole fraction solute.

The data are shown in Table 2.

3.2.2. Excess Viscosity. The mixing of different compounds gives rise to solutions that generally do not behave ideally. The deviation from ideality is expressed by many thermodynamic properties, particularly by excess or residual extensive properties. Excess thermodynamic properties of mixtures correspond with the difference among the actual property and the property if the system behaves ideally and thus are useful in the study of molecular interactions and arrangements. In particular, they reflect the interactions that take place among solute-solute, solute-solvent, and solventsolvent species. The excess viscosity $\left(\eta^{E}\right)$ has been evaluated from the observed viscosity of the solution and that of its pure components using the relation [3]

$$
\eta^{E}=\eta-\left(X_{1} \eta_{1}+X_{2} \eta_{2}\right)
$$

where $\eta_{2}=$ viscosity of solute.

The data presented in Table 2 show that the $\eta^{E}$ values are positive in the entire concentration range at both the temperatures. This shows the presence of specific solutesolvent interactions such as hydrogen bond formation in these systems [4].

3.3. B-Coefficients. The Jones-Dole equation was used to analyze the viscosities following the equation [5]

$$
\eta_{r}=\frac{\eta}{\eta_{1}}=1+A c^{1 / 2}+B c
$$

where $A=$ constant characteristic of ion-ion interactions, $B=$ constant characteristic of ion-solvent interactions, and $c$ $=$ molar concentrations.

The values of relative viscosities are presented in Table 3. The Falkenhagan coefficient $A$ is also given for electrolytes. The $B$-coefficients obtained as slope of straight line have been recorded in Table 3.

Einstein [6] proposed an equation

$$
\eta=\eta_{1}(1+2.5 v)
$$

where $v=$ aggregate volume of the particles in a unit volume of solution.

The previous equation describes the concentration dependence of the relative viscosity of solution of electrolyte. The coefficient of $v$ is $2.5 v$. The term $2.5 v$ is taken to be valid for electrolyte and it is equivalent to the product in $B C$ in the Jone-Doles equation. The data are presented in Table 3. 
3.4. Activation Parameter. The viscosity data have also been analyzed on the basis of a transition state theory of relative viscosity as suggested by Rama Rao et al. [7]. The viscosity $B$-coefficient is expressed by equation

$$
B=\frac{\left(\bar{V}_{1}^{0}-\bar{V}_{2}^{0}\right)}{1000}+\frac{\left[\left(\bar{V}_{1}^{0} / 1000\right) \Delta \mu_{2}^{0 \neq}-\Delta \mu_{1}^{0 \neq}\right]}{\mathrm{RT}},
$$

where $\bar{V}_{1}^{0}=$ partial molar volume of solvent, $\bar{V}_{2}^{0}=$ partial molar volume of solute, $\Delta \mu_{1}^{0 \neq}=$ free energy of activation per mole of solvent, $\Delta \mu_{2}^{0 \neq}=$ free energy of activation per mole of solute, $B=$ viscosity $B$-coefficient. $R=$ universal Gas constant $\left(8.314 \mathrm{JK}^{-1} \mathrm{~mol}^{-1}\right)$, and $T=$ temperature $\left(303.15^{\circ} \mathrm{K}\right)$.

3.4.1. Solvent Activation Parameter: $\Delta \mu_{1}^{0 \neq} \cdot \Delta \mu_{1}^{0 \neq}$ is calculated from equation proposed by Eying et al.

$$
\Delta \mu_{1}^{0 \neq}=\mathrm{RT} \operatorname{In}\left(\frac{\eta_{1} \bar{V}_{1}^{0}}{H N}\right)
$$

where $N=$ Avogadro's number $\left(6.023 \times 10^{23} \mathrm{gm} \cdot\right.$ atom $), H=$ Planck's constant $\left(6.626 \times 10^{-34} \mathrm{~J} \cdot \mathrm{sec}\right)$, and $\eta_{1}=$ viscosity of solvent.

3.4.2. Solvent Activation Parameter: $\Delta \mu_{2}^{0 \neq}$. Solvent activation parameter, $\Delta \mu_{2}^{0 \neq}$, is derived from following expression:

$$
\Delta \mu_{2}^{0 \neq}=\Delta \mu_{1}^{0 \neq}+\left(\frac{\mathrm{RT}}{\bar{V}_{1}^{0}}\right)\left[1000 B-\bar{V}_{1}^{0}-\bar{V}_{2}^{0}\right) .
$$

The values of solvent $\Delta \mu_{1}^{0 \neq}$ and solute $\Delta \mu_{2}^{0 \neq}$ and activation free energies are given in Table 4.

According to Feakins model, the greater the value of $\Delta \mu_{2}^{0 \neq}$ is, the greater the structure ability of the solute is. The values of $\Delta \mu_{2}^{0 \neq}$ are very large as compared to those of $\Delta \mu_{1}^{0 \neq}$, which suggests that the formation of transition state is accompanied with breaking and distortion of intermolecular bonds.

\subsection{Excess Free Energy of Activation for Viscous Flow $G^{E}$ and Interaction Parameter d}

3.5.1. Excess Free Energy of Activation for Viscous Flow $G^{E}$. The extra-thermodynamic property, excess Gibb's free energy of activation of flow $\left(G^{E}\right)$ for the solution has been computed from the Eyring equation [8]

$$
G^{E}=\operatorname{RT}\left[\operatorname{In} \eta V-\left(X_{1} \operatorname{In} \eta_{1} V_{1}+X_{2} \operatorname{In} \eta_{2} V_{2}\right)\right]
$$

The values are listed in Table 5. The value of $G^{E}$ increases with the increase in concentration of solute and also increases with the increase in temperature suggesting the interactions became stronger.
TABLE 3: $B$-coefficient, $A, B$ of tris (hydroxymethyl)amino methane hydrochloride in $20 \%(\mathrm{v} / \mathrm{v})$ acetone-water system at $303.15^{\circ} \mathrm{K}$.

\begin{tabular}{lccc}
\hline $\begin{array}{l}\text { Concentration } \\
\left(\mathrm{mol} \mathrm{dm}^{-3}\right)\end{array}$ & $B c$ & $A$ & $B$ \\
\hline 0.0100 & -0.0057 & & \\
0.0200 & -0.0458 & & \\
0.0300 & -0.0959 & & \\
0.0400 & -0.1178 & & -6.5591 \\
0.0500 & -0.2099 & 0.1031 & \\
0.0600 & -0.2612 & & \\
0.0700 & -0.3331 & & \\
0.0800 & -0.4065 & & \\
0.0900 & -0.4789 & & \\
0.1000 & -0.6214 & & \\
\hline
\end{tabular}

TABLE 4: Activation parameters of tris (hydroxymethyl)aminomethane hydrochloride in $20 \%(\mathrm{v} / \mathrm{v})$ acetone-water system at $303.15^{\circ} \mathrm{K}$.

\begin{tabular}{lcc}
\hline $\begin{array}{l}\text { Concentration } \\
\left(\mathrm{mol} \mathrm{dm}^{-3}\right)\end{array}$ & $\begin{array}{c}\Delta \mu_{1}^{0 \neq} \\
\left(\text { in kJ mol }^{-1}\right) 10^{5}\end{array}$ & $\begin{array}{c}\Delta \mu_{2}^{0 \neq} \\
\left(\mathrm{in} \mathrm{kJ} \mathrm{mol}^{-1}\right) 10^{5}\end{array}$ \\
\hline 0.0100 & 2.6244 & -6.4836 \\
0.0200 & 2.6283 & -6.4798 \\
0.0300 & 2.6329 & -6.4752 \\
0.0400 & 2.6348 & -6.4732 \\
0.0500 & 2.6426 & -6.4654 \\
0.0600 & 2.6467 & -6.4613 \\
0.0700 & 2.6522 & -6.4558 \\
0.0800 & 2.6575 & -6.4505 \\
0.0900 & 2.6624 & -6.4456 \\
0.1000 & 2.6714 & -6.4365 \\
\hline
\end{tabular}

TABLE 5: Excess molar free energy of activation of flow $\left(G^{E}\right)$ and Grunberg and Nissan constant tris (hydroxymethyl)amino methane hydrochloride in $20 \%(\mathrm{v} / \mathrm{v})$ acetone-water system at $303.15^{\circ} \mathrm{K}$.

\begin{tabular}{lcc}
\hline $\begin{array}{l}\text { Concentration } \\
\left(\mathrm{mol} \mathrm{dm}^{-3}\right)\end{array}$ & $\begin{array}{c}\text { Excess molar free energy } \\
\text { of activation of flow }\left(G^{E}\right)\end{array}$ & $\begin{array}{c}\text { Grunberg and Nissan } \\
(d)\end{array}$ \\
\hline 0.0100 & 16.9678 & 0.0001 \\
0.0200 & 56.1698 & 0.0004 \\
0.0300 & 103.0463 & -0.0012 \\
0.0400 & 122.8588 & -0.0007 \\
0.0500 & 202.7112 & -0.0003 \\
0.0600 & 243.5637 & -0.0002 \\
0.0700 & 299.0243 & -0.0002 \\
0.0800 & 351.6797 & -0.0003 \\
0.0900 & 401.7946 & -0.0001 \\
0.1000 & 494.6975 & -0.0001 \\
\hline
\end{tabular}

3.5.2. Interaction Parameter $d$. The impact of solute on viscosity is understood in terms of parameter $d$, which is regarded as a measure of the strength of interaction 
between components of solution. It has been estimated using relationship proposed by Gruenberg and Nissan [9]

$$
\operatorname{In} \eta=X_{1} \operatorname{In} \eta_{1}+X_{2} \operatorname{In} \eta_{2}+X_{1} X_{2} d,
$$

where $d=$ Grunberg and Nissan parameter:

$$
D \propto \frac{W}{\mathrm{RT}}
$$

where $W=$ interaction energy.

The values of $d$ are reported in Table 5 .

\section{Conclusion}

Knowledge of transport properties is important in all these applications to understand the molecular interactions. Viscosity increases as a function of concentration and decreases in increase in temperatures. The values of $B$-coefficient show solute-solvent interactions in the present systems. The values, $\Delta \mu_{2}^{0 \neq}$, are very large as compared to those of $\Delta \mu_{1}^{0 \neq}$ which suggests that the formation of transition state is accompanied with breaking and distortion of intermolecular bonds. Volumetric data are used to test molecular theories or models of solution to extend our understanding about molecular interactions among components.

\section{Conflict of Interests}

The author declare that she has no commercial relations with MFG Company.

\section{References}

[1] S. S. Yadava, Y. Singh, and N. Kushwaha, "Densities and viscosities of alkylethanoates +cyclohexane, +benzene, +1,4dimethylbenzene, and +1,3.5-trimethylbenzene at $308.15 \mathrm{~K}$," Acta Chimica Slovenica, vol. 57, no. 3, pp. 707-715, 2010.

[2] X. Z. Yang and J. Wang, "Densities and viscosities of $1,1^{\prime}$ (pentane-1,5-diyl)-bis(pyridinium) dibromide in ethanol + water from (293.15 to 344.15) K," Journal of Chemical \& Engineering Data, vol. 55, no. 6, pp. 2322-2325, 2010.

[3] G. Jones and M. Dole, "The viscosity of aqueous solutions of strong electrolytes with special reference to barium chloride," Journal of the American Chemical Society, vol. 51, no. 10, pp. 2950-2964, 1929.

[4] D. Feakins, D. J. Freemantle, and K. G. Lawerence, “Transition state treatment of the relative viscosity of electrolytic solutions. Applications to aqueous, non-aqueous and methanol + water systems," Journal of the Chemical Society, Faraday Transactions 1, vol. 70, pp. 795-806, 1974.

[5] M. I. Aralaguppi, T. M. Aminabhavi, R. H. Balundgi, and S. S. Joshi, "Thermodynamic interactions in mixtures of bromoform with hydrocarbons," Journal of Physical Chemistry, vol. 95, no. 13, pp. 5299-5308, 1991.

[6] A. Pal and A. Kumar, "Viscosity of 1-propanol + ethylene glycol dimethyl, + diethylene glycol dimethyl, + tri-ethylene glycol dimethyl, and + tetraethylene glycol dimethyl ethers at 288.15, 298.15 and 308.15 K," Indian Journal of Chemistry A, vol. 42, no. 11, pp. 2708-2716, 2003.
[7] G. V. Rama Rao, A. V. Sarma, and C. Rambabu, "Evaluation of excess thermodynamic properties in some binary mixtures of o-chlorophenol," Indian Journal of Chemistry A, vol. 43, no. 12, pp. 2518-2528, 2004.

[8] L. Grunberg, "The viscosity of regular solutions: systems involving carbon tetrachloride, benzene and cyclohexane," Transactions of the Faraday Society, vol. 50, pp. 1293-1303, 1954.

[9] L. Grunberg and A. H. Nissan, "Mixture law for viscosity," Nature, vol. 164, no. 4175, pp. 799-800, 1949. 

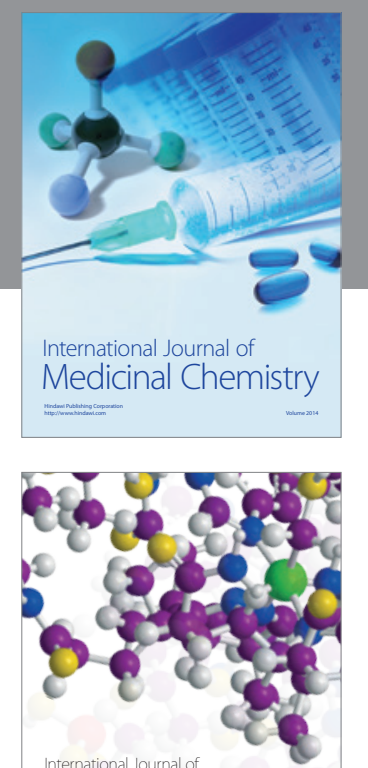

\section{Carbohydrate} Chemistry

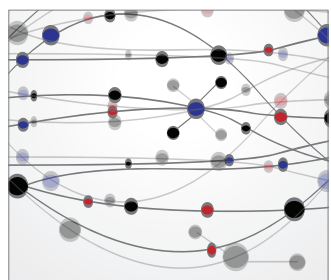

The Scientific World Journal
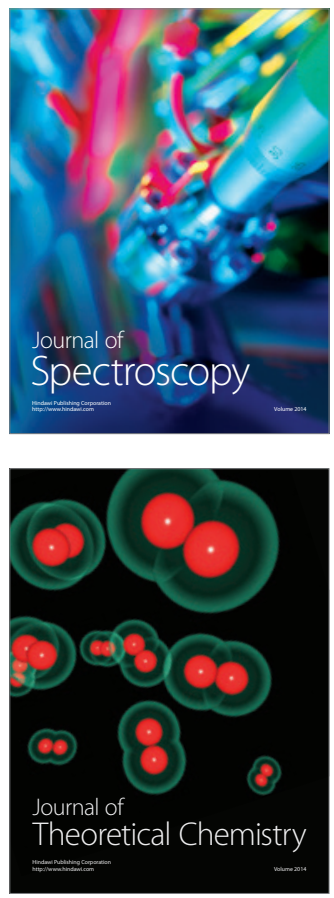
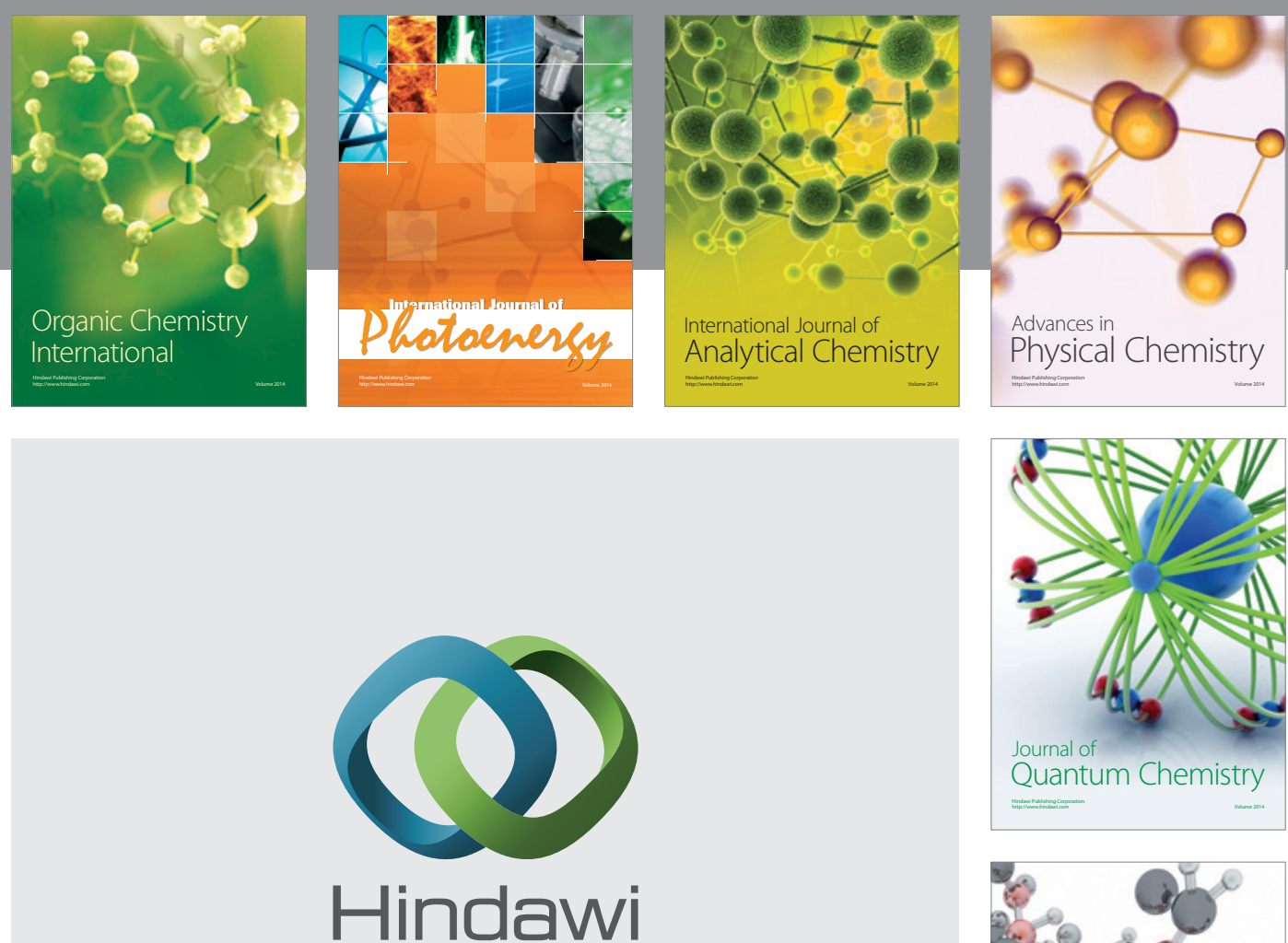

Submit your manuscripts at

http://www.hindawi.com

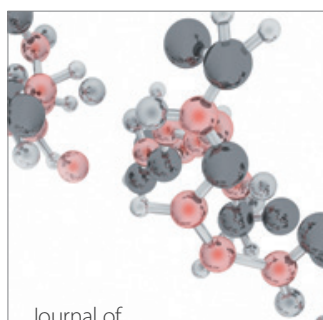

Analytical Methods

in Chemistry

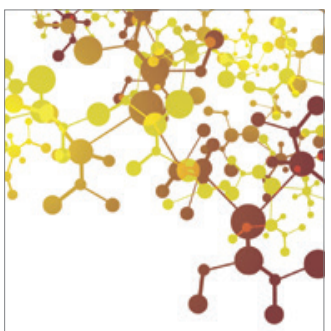

Journal of

Applied Chemistry

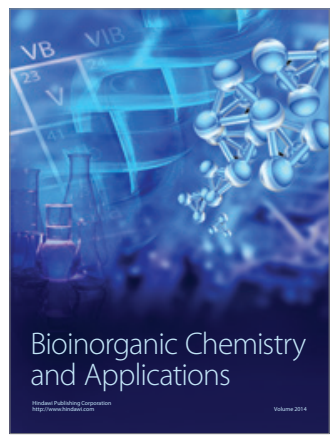

Inorganic Chemistry
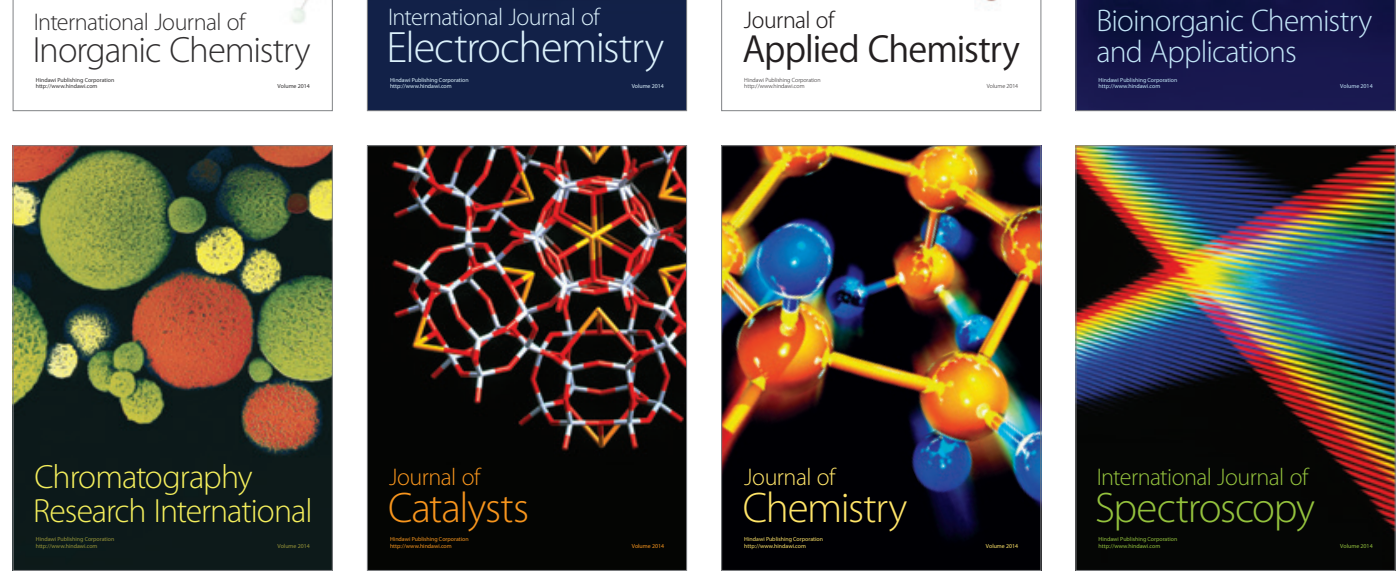